\title{
Mathematical modeling of electromagnetic environment at railroad junctions
}

\author{
Natalya Buyakova ${ }^{1, *}$, Vasiliy Zakaryukin ${ }^{2}$, and Andrey Kryukov ${ }^{2,3}$ \\ ${ }^{1}$ Angarsk State Technical University, ul. Chaykovskogo, 60, 665835, Angarsk, Russia \\ ${ }^{2}$ Irkutsk State Transport University, ul. Chernyshevskogo, 15, 664074 Irkutsk, Russia \\ ${ }^{3}$ Irkutsk national research technical university, st. Lermontova, 83, 664074 Irkutsk, Russia
}

\begin{abstract}
Results of computer-aided studies of electromagnetic environment at railroad junctions of alternating current electrified railroads having voltage of $25 \mathrm{kV}$ are presented. A large number of lines and overhead catenaries significantly complicate the picture of electromagnetic field distribution. The nature of the field distribution in space is significantly affected by the rolling stock on station tracks. Besides, the task of electromagnetic environment modeling is complicated by the presence of underground pipelines and enclosures, and reinforced concrete passenger platforms. During the transfer of power of $10+\mathrm{j} 10 \mathrm{MV} \cdot \mathrm{A}$ through the junction of overhead system, the magnetic field strength at a level of $1,8 \mathrm{~m}$ is considerably less than the magnetic strength at a railway haul due to current distribution on overhead system of several tracks. Magnetic field strength levels in calculation examples do not exceed amplitude of $30 \mathrm{~A} / \mathrm{m}$. The train performance leads to changes in the strengths of the electrical and magnetic fields. The dynamics of changes is presented as a result of simulation modeling of train movement modes.
\end{abstract}

\section{Introduction}

A combination of electromagnetic processes in a given area of space is characterized by the term of electromagnetic environment (EME). The main features of these processes are electrical and magnetic fields' strengths [1 - 12]. In a number of cases, especially, when the railroad track goes through a residential area, the levels of electromagnetic fields (EMF) strengths created by electrical traction network can exceed the permissible norms [1]. Thus, electromagnetic environment determines the conditions of electromagnetic safety. The tasks of EME modeling are especially important at the railroad junctions. These facilities are subject to stricter electromagnetic safety regulations due to a possibility of a large number of people occurring there. The junctions have a large number of tracks and overhead catenaries, which significantly complicates the picture of EMF distribution [1, 13 -17]. Besides, the nature of EMF spatial distribution is significantly affected by metal cars and cisterns that can stay at station tracks for a long time. One more factor complicating the task of EMF modeling at railroad junctions is the presence of metal pipelines which also

*Corresponding author: bn_900@mail.ru 
affect the EMF distribution pattern. The article contains the results of computer-aided studies of the above factors.

\section{Modeling methods}

The staff of the Irkutsk State Transport University (Russia) have developed methods of traction energy systems (TES) modeling in phase coordinates [18 - 20], based on the use of lattice equivalent networks (LEN) of multi conductor elements that are basically RLC elements connected to complete graphs circuits. The following formalized definition can be written for LEN:

$$
T E C: h u b \bigcup c o n, \forall i, j \subset h u b \rightarrow \operatorname{con}_{i, j} \subset c o n,
$$

where TEC - LEN designation; hub - node set; con - branch set. Using LEN of individual elements, lattice network is implemented which complies with three-singlephase network of Railroad Power System:

$$
T E C_{\Sigma}=\bigcup_{k=1}^{n} T E C_{k},
$$

where symbol $U$ denotes a combination of individual elements LEN based on specific network topology.

Conductivity matrix is generated based on $T E C_{\Sigma}$

$$
\mathrm{A}: T E C_{\Sigma} \rightarrow \underline{\mathbf{Y}}_{\Sigma}=\mathbf{M}_{0} \underline{\mathbf{Y}}_{V} \mathbf{M}_{0}^{T},
$$

where $\underline{\mathbf{Y}}_{V}$ - block-diagonal matrix whose blocks comply with conductivity matrixes of specific elements; $\mathbf{M}_{0}-$ generalized incidence matrix. Non-linear equations describing a combination of Railroad Power System modes for train performance are generated using $\underline{\mathbf{Y}}_{\Sigma}:$

$$
\underline{\mathbf{Y}}_{\Sigma}\left(t_{k}\right) \dot{\mathbf{U}}\left(t_{k}\right)=\operatorname{diag} \frac{1}{\widetilde{U}_{j}\left(t_{k}\right)} \cdot \widetilde{\mathbf{S}}\left(t_{k}\right) ; j=\overline{1 . . n} ; k=1 . . m
$$

where $\dot{\mathbf{U}}$ - nodal voltages vector; $\tilde{\mathbf{S}}=\left[\begin{array}{lllllll}\widetilde{S}_{1} & \widetilde{S}_{2} & \ldots & \widetilde{S}_{j} & \ldots & \widetilde{S}_{n}\end{array}\right]^{T} ; \tilde{S}_{j}, \tilde{U}_{j}-$ power and voltage conjugated complexes of $\mathrm{j}$-th network node. After the separation of the real and imaginary components, a final model is formed, which in general form can be written as follows

$$
\mathbf{F}_{k}\left[\mathbf{V}\left(t_{k}\right), \mathbf{X}\left(t_{k}\right)\right]=\mathbf{0}, k=1 . . . m,
$$

where $\mathbf{F}$ - non-linear vector function; $\mathbf{V}$ - the controlled parameters vector (independent variables); $\mathbf{X}$ - the uncontrolled parameters vector (dependent variables).

The described modeling technology is implemented in Fazonord software [19]. The calculations with software application were subject to repeated checks calculation results comparison with field measurements data.

\section{Stationary modes modeling results}

The study of electromagnetic environment was performed for a typical traction network case of $27,5 \mathrm{kV}$ railroad junction with eight overhead catenaries. The traction network 
length is $2 \mathrm{~km}$. The tracks overhead system is made of PBSM-95+MF-100 wires, while the track - of R-65 rails. Power transfer beyond the junction overhead system for two railway haul tracks makes $8+j 8 \mathrm{MV} \cdot \mathrm{A}$ for each of the tracks. Coordinates of the conductive parts contact wires, messenger wires, and tractive rails are given in fig. 1 .

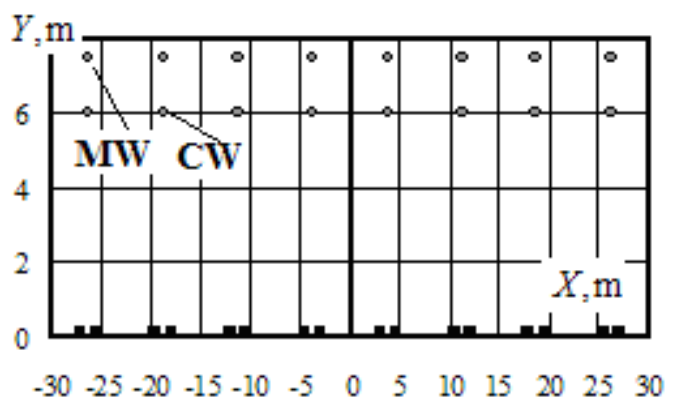

Fig. 1. Coordinates of wires and rails location: $\mathrm{MW}$ - messenger wire, $\mathrm{CW}$ - contact wire.

The results of EMF strengths definition at 1,8 $\mathrm{m}$ height are given in fig. 2,3.

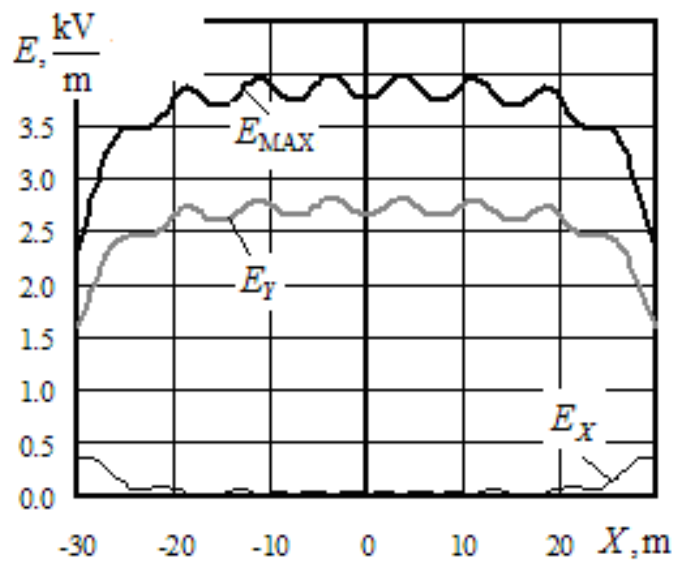

Fig. 2. Amplitudes and electrical field strength components at a height of $1,8 \mathrm{~m}$.

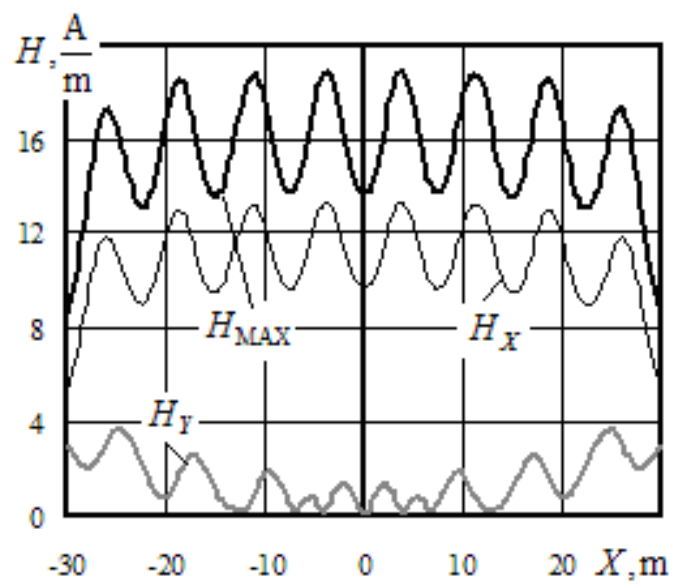

Fig. 3. Amplitudes and magnetic field strength components at a height of $1,8 \mathrm{~m}$. 
From the presented results, it can be concluded that the EMF strength levels do not exceed the norm of $80 \mathrm{~A} / \mathrm{m}$ set for the operating personnel, but can exceed the permissible values for the residential area.

\section{Electromagnetic field with trains' moving}

The presented dependence curves give a complete picture of the electromagnetic situation at the railway junction for a particular traction network mode. Due to the sharply varying nature of the traction load, the electromagnetic situation at the railway junctions is continuously changing. Therefore, EMF calculations performed for specific values of currents in overhead catenaries are not informative to the full extent. It is possible to overcome this difficulty via obtaining the dynamics of EMF changes in the simulation of real train traffic schedules. As an example, the results of magnetic field strengths dynamics calculation during the train operation are presented. The operation of 23 trains with weights of 2700-3400 tons in odd direction and 16 trains with weights of 4500-6000 tons in the even direction was considered. Power flows through the traction network were distributed from the railway haul to the junction overhead catenaries connected in parallel, which leads to a decrease in the magnetic field. Summary results of the system operation modeling during the trains operation are shown in fig. 4 and 5.

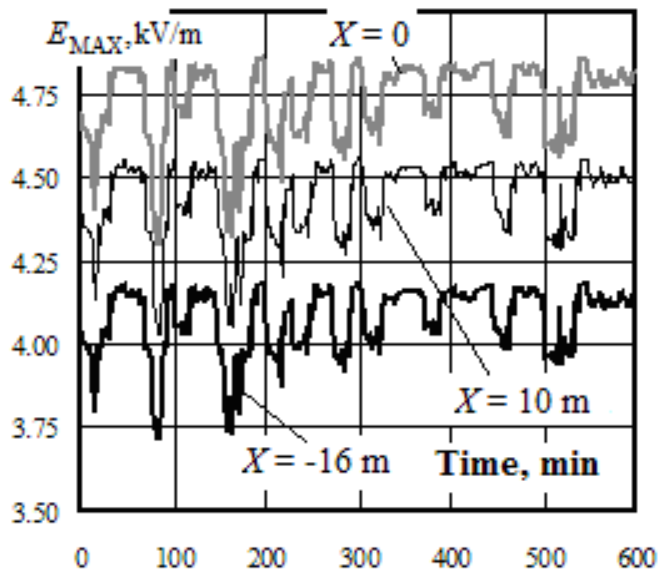

Fig. 4. The time dependences of the electrical field strengths for different values of $X$ coordinate.

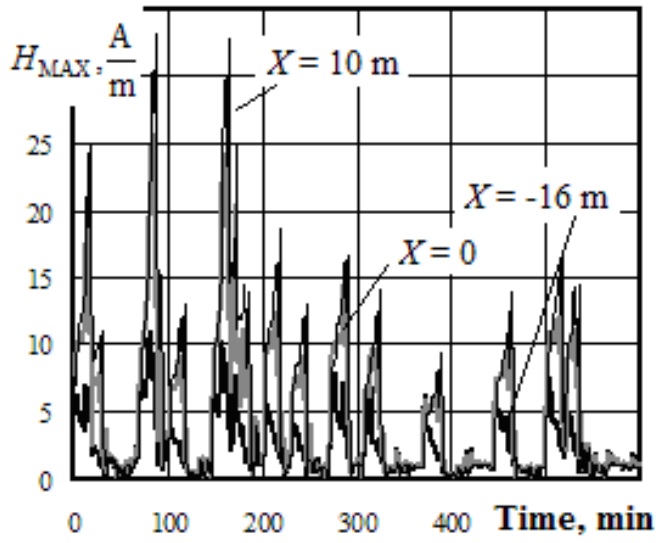

Fig. 5. The time dependences of the magnetic field strengths for different values of $\mathrm{X}$ coordinate. 
The following conclusions can be drawn based on the above said.

1. The magnetic field strengths created by the traction network with eight overhead catenaries do not exceed the maximum level of $80 \mathrm{~A} / \mathrm{m}$, set for operating personnel, but can exceed the permissible values for residential areas.

2. Simulation of the field change dynamics makes it possible to obtain the most complete picture of the electromagnetic environment at railway junctions. The results of the like modeling can be used to develop measures to increase the electromagnetic safety level.

\section{Taking into account the rolling stock effect}

The EMF calculation technique considered in this paper is applicable to the calculation of electromagnetic fields created by traction networks of any complexity, in particular, by traction networks at railway junctions with a considerable number of tracks and overhead catenaries and the presence of rolling stock on junction tracks.

At large stations there are always metal cars and cisterns that can significantly change the magnetic field strength distribution pattern. The Fazonord software application allows the use of up to several hundred wires in the model, which makes it possible to model wagons and cisterns with a set of grounded wires arranged so that the distances between the wires are much less than the distance from these wires to the observation point.

To illustrate the modeling capabilities, a typical situation of a railway junction with eight electrified tracks was chosen, the traction network section of which is shown in fig. 6 . The two main ways of the station are free from trains, the cars and cisterns are on the side tracks. In the calculations, trackways were taken into account as separate grounded conductors.

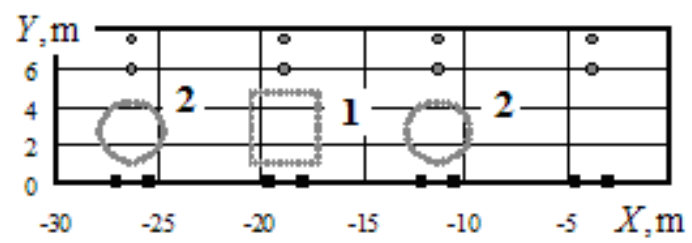

a)

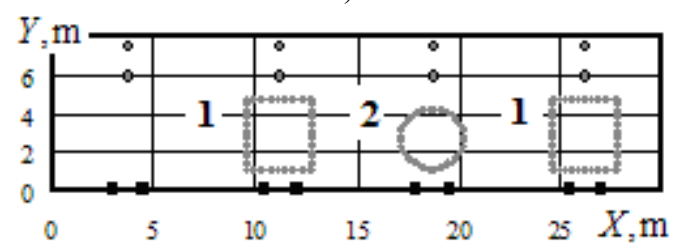

b)

Fig. 6. Coordinates of a multi wire system wires at a rolling stock presence: $a$ - odd gridiron; $\sigma$ - even gridiron; 1 - cars; 2 - cisterns.

The following parameters were used for modeling the modes and calculating the EMF strengths:

- the length of the eight-track section of the traction network is $2 \mathrm{~km}$;

- two loads of $10+j 10 \mathrm{MV} \cdot \mathrm{A}$ are applied at the end of the section with overhead catenaries connected in parallel of odd and even directions, respectively.

The results obtained during modeling in Fazonord PC are presented in table. I and are illustrated in fig. 7, 8 with dependences curves of the EMF strengths amplitudes on the $X$ coordinate. 
Table 1. Maximal and average emf strengths values at a height of $1.8 \mathrm{~m}$ in the range of $\mathrm{x}$ coordinate change from $-30 \mathrm{~m}$ to $+30 \mathrm{~m}$.

\begin{tabular}{|l|c|c|c|c|}
\hline \multirow{2}{*}{ Parameter } & \multirow{2}{*}{ Value } & $\begin{array}{c}\text { No cars and } \\
\text { cisterns }\end{array}$ & $\begin{array}{c}\text { Cars and cisterns } \\
\text { available }\end{array}$ & Difference, \% \\
\hline \multirow{2}{*}{ Maximum } & \multirow{2}{*}{ Emax } & 3,63 & 1,78 & 51,0 \\
\cline { 1 - 3 } Average & 3,99 & 3,51 & 11,8 \\
\hline \multirow{2}{*}{ Maximum } & \multirow{2}{*}{$\operatorname{Hmax}$} & 15,4 & 6,43 & 58,2 \\
\cline { 1 - 3 } Average & 18,8 & 13,0 & 31,1 \\
\hline
\end{tabular}

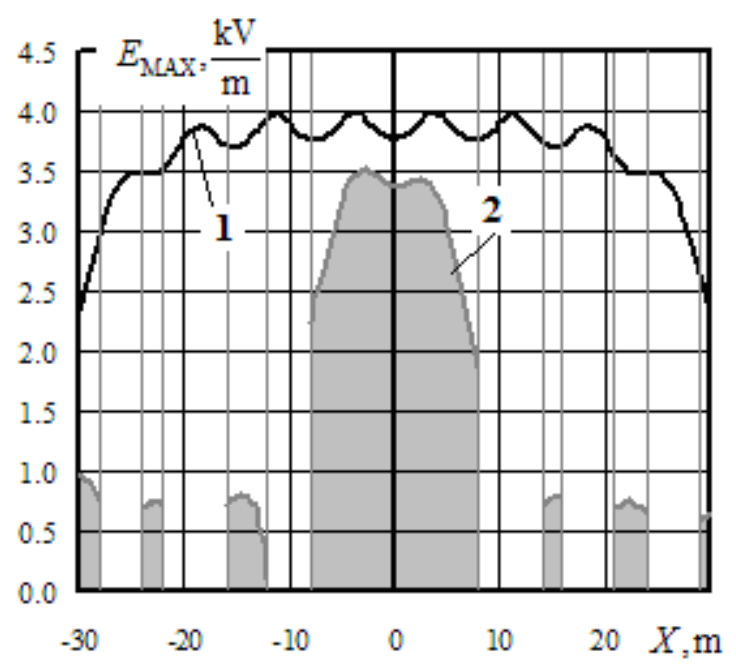

Fig. 7. Amplitudes of the electrical field strength at a height of $1.8 \mathrm{~m}: 1$ - no rolling stock; 2 - the rolling stock available.

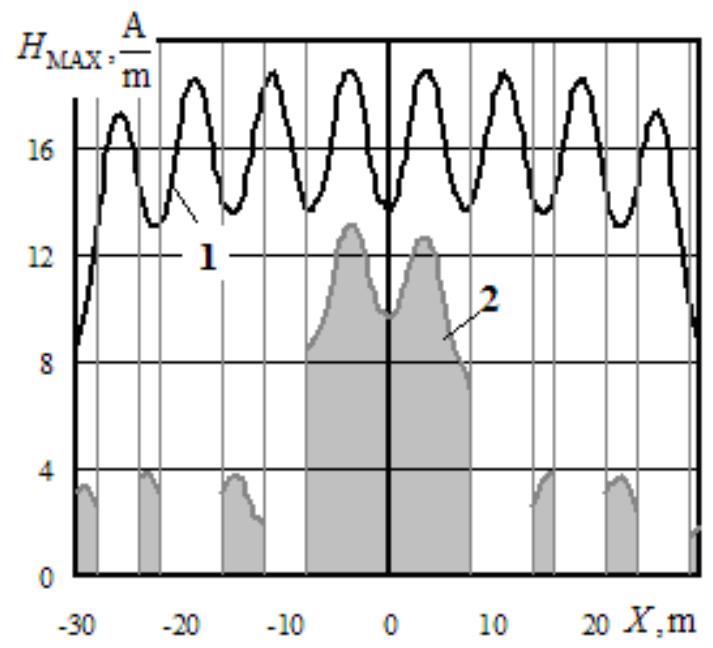

Fig. 8. Amplitudes of the magnetic field strength at a height of $1.8 \mathrm{~m}: 1$ - no rolling stock; 2 - the rolling stock available.

The modeling results allow formulation of the following conclusions.

1. The electrical and magnetic fields strengths created by the traction network, including eight overhead catenaries and 16 rails, do not exceed the permissible level that is set for the 
operating personnel. However, these values can exceed the limit values for residential areas.

2. The modeling results showed that in the presence of cars and cisterns on the junction tracks, the extreme values of the electrical field strengths are reduced by $50 \%$, and the magnetic field strength values - by $58 \%$. On average, the differences are 11 and $31 \%$, respectively.

Thus, the technology of electromagnetic fields computer-aided modeling allows taking into account the influence of metal cars and cisterns located at junctions.

\section{Taking into account the passenger platforms}

One of the significant factors that can lead to a noticeable increase in the strengths of electrical and magnetic fields is the presence of passenger platforms with extended and grounded metal parts. To reveal the regularities of the electromagnetic environment at such stations, a modeling of an eight-track traction network of $27,5 \mathrm{kV}$ with reinforced concrete passenger platforms, was performed.

The voltage of the overhead system is assumed equal to $27,5 \mathrm{kV}$. Power transfer beyond the junction overhead system for two railway haul tracks is $10+j 10$ MVA for each path. The simulation results are shown in fig. 9, 10 .

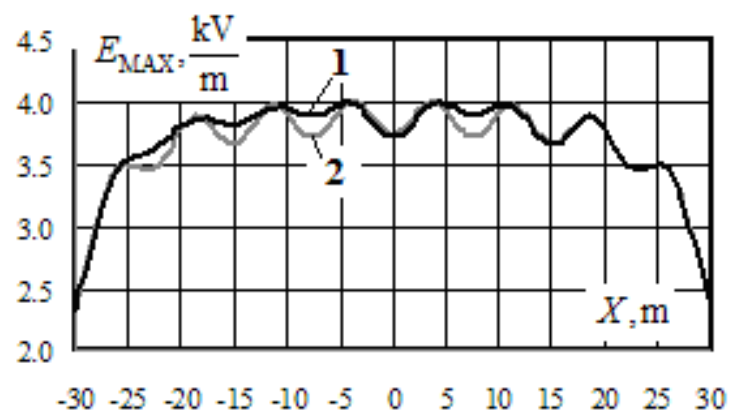

Fig. 9. Dependence of the electrical field strength on $X$ coordinate at a height of $2.1 \mathrm{~m}: 1$ - platforms; 2 - no platforms.

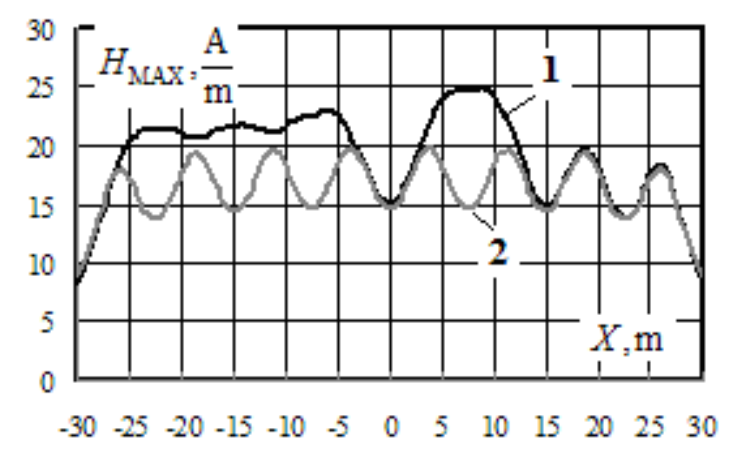

Fig. 10. Dependence of the magnetic field strength on $X$ coordinate at a height of $2.1 \mathrm{~m}: 1-$ platforms; 2 - no platforms.

From the above dependences it can be seen that the passenger platforms virtually do not affect the electrical field strength, but they increase the magnetic field strength at a height of $2,1 \mathrm{~m}$ from the ground surface in the vicinity of the platforms by $15 \ldots 25 \%$. 


\section{Taking into account underground pipelines}

The technique developed allows taking into account such an important factor affecting the level of EMF, as the presence of earthed extended metal objects (pipelines, cable lines with earthed shells, earthed cables). The analysis of this factor effect was carried out by modeling $27,5 \mathrm{kV}$ traction network of a railroad junction, taking into account the pipeline made of steel pipes $300 \mathrm{~mm}$ in diameter, the pipe-earth conductivity of which is assumed to be $0,5 \mathrm{~S} / \mathrm{km}$. Levels of magnetic field strength can reach significant values due to the fact that large currents can flow through contact wires, messenger wire, rails and a pipeline (due to the magnetic influence of the traction network). The calculations are made for traction network loads equal to $10+j 10 \mathrm{MV} \cdot \mathrm{A}$.

Four options were considered for modeling:

- there is no pipeline;

- single-pipe arrangement laid at $1 \mathrm{~m}$ depth;

- two-pipe arrangement laid at the same depth;

- three-pipe arrangement laid at the same depth.

The results of calculating the magnetic field strength at a height of $1,8 \mathrm{~m}$ for options specified for a change in the coordinate $X$ from $31 \mathrm{~m}$ to $40 \mathrm{~m}$ and the location of the pipes near the coordinate $34 \mathrm{~m}$ are shown in fig. 11 .

The results of calculations show that the magnetic field strength amplitudes near the pipes are increased up to 1,5 times the value in comparison with the situation of the pipes absence. This is due to the currents induced in the grounded metal structure of the pipeline by the magnetic field of the overhead system.

This fact should be taken into account when analyzing the electromagnetic situation at railroad transport facilities and developing measures to improve it, since the influence of underground metal pipelines along the railway route may cause exceeding of norm in local areas of space. Such situation often takes place at the railroad junctions and in localities where the railroad tracks are laid within residential areas.

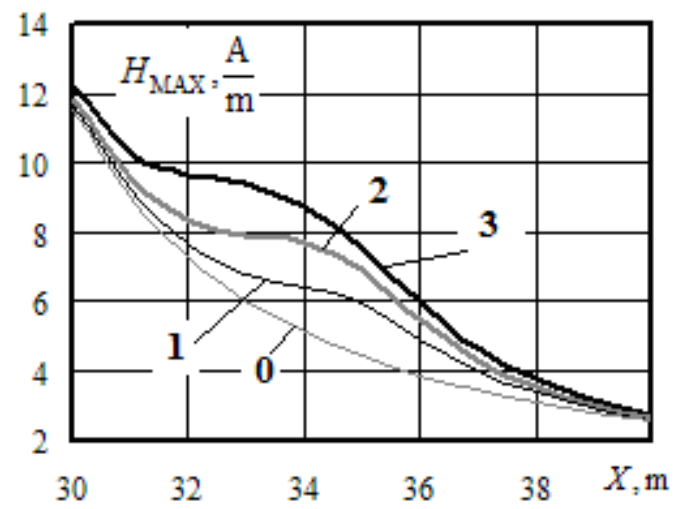

Fig. 11. The magnetic field in the pipeline vicinity.

\section{Taking into account enclosing structures}

A railroad junction can have metal enclosures capable of affecting the EMF spatial distribution pattern. The results of the magnetic field strength calculation with view to the effect of enclosing structures for power transfer of $10+j 10 \mathrm{MV} \cdot \mathrm{A}$ via two tracks beyond the junction, are presented in fig. 12. 


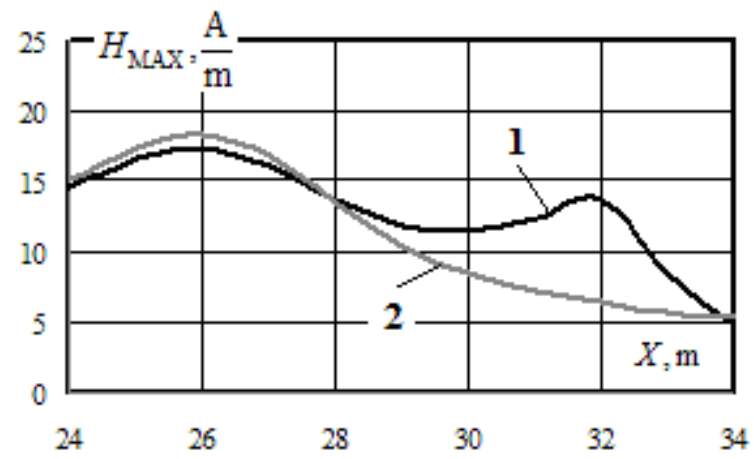

Fig. 12. Dependences of magnetic field strength on the $X$ coordinate. 1 - an enclosing structure; 2 no enclosing structure.

The presence of enclosures leads to an increase in the magnetic field average strength near the enclosure with some reduction in the maximal value, though, at 2 meters distance from the enclosure, insignificant increase in the strength is observed which ensures increase in the average value.

\section{Conclusion}

1. A large number of tracks and overhead catenaries complicate the picture of electromagnetic field distribution pattern significantly. The EMF spatial distribution pattern is significantly affected by metal cars and cisterns that can stay at station tracks for a long time. Besides, the task of junction EMF modeling is complicated by the presence of underground pipelines and enclosures, as well as reinforced concrete passenger platforms.

2. During the power transfer through the junction $10+j 10 \mathrm{MV} \cdot \mathrm{A}$ overhead system, which is close to the limit of load-carrying capacitance of one traction transformer having nominal power of 40,000 kVA, the magnetic field strength at a level of $1,8 \mathrm{~m}$ is considerably less than the magnetic strength at a railway haul due to current distribution on overhead system of several tracks. Magnetic field strength levels in calculation examples do not exceed amplitude $30 \mathrm{~A} / \mathrm{m}$.

3. Modeling of the field change dynamics makes it possible to obtain the most complete picture of the electromagnetic environment at railway junctions. The results of the like modeling can be used to develop measures to increase the electromagnetic safety level.

4. The presence of the rolling stock and passenger platforms changes the EMF spatial strengths distribution pattern essentially when compared with the situation when these elements are absent. Due to the presence of the rolling stock, the electromagnetic energy density on passenger platforms and the EMF harmful effects on the human body are significantly reduced. Cars and cisterns on the junction tracks lead to the electrical field strength reduction approximately by $50 \%$, while the magnetic one - by $58 \%$.

5. The growth of the field strength in the space located above the pipeline, takes place due to the currents induced in the grounded metal structure of the pipeline. The presence of junction tracks' metal enclosures leads to the increase in the magnetic field in their vicinity.

\section{References}

1. N.V. Buyakova, V.P. Zakaryukin, A.V. Kryukov, Electromagnetic safety in railroads power supply systems: modeling and control (Angarsk, 2018)

2. L.M. Wedepohl, D.J Wilcox, Proc. IEE 120, 253-260 (1973) 
3. S.M. Apollonskiy, Problems of electromagnetic safety on electrified railway. Electromagnetic safety on railway with alternating current in the traction power network (Moscow, 2017)

4. S.M. Apollonsky, A.N. Gorsky, Safety of human activity in electromagnetic fields (SPb, 2004)

5. S.M. Apollonsky, A.N. Gorsky, Calculations of electromagnetic fields (Moscow, 2006)

6. V.N. Dovbysh, M.Yu. Maslov, Yu.M. Spodobayev, Electromagnetic safety of electric system elements (Samara, 2009)

7. B. Blake Levitt, Protection from electromagnetic fields. On impact of electric appliances, mobile phones, electric power lines and other devices on human body (Moscow, 2007)

8. B.A. Dudin, Calculation of electric and magnetic field in multi wire overhead lines (Moscow, 2005)

9. A.N. Gorsky, L.K. Vasilieva, Electromagnetic emissions and protection from them $(\mathrm{SPb}, 2000)$

10. V. Gurevich, Components and Technologies 2, 80-84 (2010)

11. V. Gurevich, Components and Technologies 3, 91-96 (2010)

12. V. Gurevich, Components and Technologies 4, 91-96 (2010)

13. A. Steimel, Electric traction motive power and energy supply. Basics and practical experience (Oldenbourg Industrieverlag, Munchen, 2008)

14. H. Biesenack, E. Braun, G. George, Energieversorgung elektrischer bannen (Verlag, Wiesbaden, 2006)

15. A. Ogunsola, A. Mariscotti, Electromagnetic Compatibility in Railways (Springer, London, 2013)

16. A.V. Kryukov, V.P. Zakaryukin, N.V Buyakova, Control of electromagnetic environment in railway traction power networks (Angarsk, 2014)

17. A.V. Kryukov, V.P. Zakaryukin, N.V Buyakova, Electromagnetic environment at the railway transport facilities (Irkutsk, 2011)

18. V. Zakaryukin, A. Kryukov, A. Cherepanov, Springer, Cham 692, 91-99 (2017), EMMFT 2017. Advances in Intelligent Systems and Computing, 1350 (2017)

19. V.P. Zakaryukin, A.V. Kryukov, Multifunctional Mathematical Models of Railway Electric Systems, 504-508 (2008), Innovation and Sustainability of Modern Railway, 645 (2008)

20. A.V. Kryukov, V.P. Zakaryukin, N.V Buyakova, The power grid of the future, Ottovon-Guericke University Magdeburg, 39-44 (2013) 